\title{
Thermodynamic Study of Light Organic Molecules Adsorption onto ZK-4 Zeolite
}

\author{
Nabila CHALAL, Hadj HAMAIZI, Maria Del Mar SOCIAS VICIANA, Benaouda BESTANI \\ and Abd-El-Kader BENGUEDDACH ${ }^{1}$. \\ Nabila CHALAL, University of Oran, Oran-Menaouer PO Box 1524, Oran, Algeria, \\ E-mail: nabila_chaalal@hotmail.fr; Tel: +213-772 026217 \\ Hadj HAMAIZI, University of Oran, Oran-Menaouer PO Box 1524, Oran, Algeria, \\ E-mail: hamaizimizou@yahoo.fr; Tel: +213-550 462417
}

Maria Del Mar SOCIAS VICIANA, University of Almería, La Cañada San Urbano S/N 04120 Almería, España.

\section{E-mail: msocias@ual.es}

Benaouda BESTANI, Dr., Université de Mostaganem, PO Box 188, Mostaganem, Algérie.

\section{E-mail: bestanib@yahoo.fr}

Abd-El-Kader. BENGUEDDACH, University of Oran, Oran-Menaouer PO Box 1524, Oran, Algeria,

E-mail: abengueddach@gmail.com; Tel: +213-558 047969

${ }^{*}$ Corresponding author: HAMAIZI Hadj, E-mail: hamaizimizou@yahoo.fr; Tel: +213-550-462417; fax: +213$41513077 / /+213-41416021$

\section{ABSTRACT}

In this work, we were interested to the interactions of various light gases (critical temperature not exceeding $31^{\circ} \mathrm{C}$ ) with the zeolite ZK-4 and its varieties exchanged at temperatures close to ambient. The interest first practice since these gases are frequently encountered in industry, and most separations, that concern them by pressure swing adsorption (PSA) are carried at room temperature. By working in these conditions, we will be in the scope of application of Henry's law, which will allow us to better characterize the adsorption of the first molecules (gas-solid interaction). The thermodynamic study should enable us to identify the type of adsorption (localized, non-localized) by applying a theoretical model explaining the experimental results. The choice of the adsorbate was guided by the behavior of the introduced molecules toward the compensating cations present in the zeolite framework. These probe molecules having a specific interaction with zeolitic cations: $\mathrm{N}_{2}, \mathrm{CO}_{2}$ (highly quadripolar), $\mathrm{C}_{2} \mathrm{H}_{4}$ (double bound) or $\mathrm{C}_{3} \mathrm{H}_{8}$ which do not exhibit neither. Final results show that adsorption of nitrogen on ZK-4 sodic form is made in a located way on five sites following Langmuir model and none of $\mathrm{CO}_{2}$ and $\mathrm{C}_{2} \mathrm{H}_{4}$ chemisorptions was revealed. Besides, the gaseous molecules interactions in presence of divalent cations replacing sodium in ZK-4 are much less higher than in the case of zeolite 4A, and are characteristic of physisorption on relatively heterogeneous sites.

Keywords: ZK-4 zeolite; Adsorption isotherm; Langmuir model; Calorimetry.

\section{Council for Innovative Research}

Peer Review Research Publishing System

\section{Journal: Journal of Advances in Chemistry}

\author{
Vol. 10, No. 7 \\ editorjaconline@gmail.com
}

www.cirjac.com 


\section{INTRODUCTION}

Zeolite ZK-4 belongs to the LTA type in the IUPAC system (Meier and Olson, 1987) and it is isomorphic to zeolite Na-A or $4 \mathrm{~A}$, which it differs only by a Si/Al greater than one (1.1 to 1.9) instead of 1 for zeolite 4A. It was synthesized for the first time by Kerr (Kerr, 1966), which established the stoichiometric domain in which it crystallizes, and then by a small number of authors (Melchior et al., 1982; Ikeda et al., 2003; Kerr, 1966; Leigenner et al., 2008; Eddy et al., 1986) who have studied the structural properties of the cubic lattice. It has been shown that the adsorption of organic molecules such as $n-$ hexane and n-octane (Kerr, 1966) on Na-ZK-4 (Si/Al=1.7) depend directly on cations $\mathrm{Na}^{+}$position even more when they are replaced by $\mathrm{K}^{+}$cations (Ikeda et al., 2008; Oh et al.,2002). Furthermore, other works (Sadlo et al., 2009) show only silver dimers are stabilized, whereas in Linde 4A silver hexamers were trapped in the sodalite cage. In this work, a certain ZK4 samples have been synthesized, cationic exchange with $\mathrm{Ni}^{2+}, \mathrm{Co}^{2+}$ and $\mathrm{Ca}^{2+}$ have been performed and finally the ration $\mathrm{Si} / \mathrm{Al}$ for each cationic variety was determined. Adsorbed quantities of nitrogen, carbon dioxide and ethylene have been measured at temperatures above Kelvin temperature and the experimental results applied to the theoretical Langmuir model using manometric adsorption technique and calorimetry. The discovery of a new catalytic material, ruthenium nanoparticles stabilized by ZK-4 zeolite framework, for this important reaction has been reported by Zahmakiran (Zahmakiran, 2012). This new catalyst system was prepared by borohydride reduction of ruthenium (III)-exchanged ZK-4 zeolite in water at room temperature. The characterization of the resulting material by advanced analytical tools shows the formation of ZK-4 zeolite dispersed ruthenium nanoparticles.

\section{EXPERIMENTAL}

\section{Chemicals}

The ZK4 zeolite synthesis requires highly reactive products; For this, we used sodium aluminate (Carlo Erba weight composition: $\mathrm{Al}_{2} \mathrm{O}_{3}=56 \%, \mathrm{Na}_{2} \mathrm{O}=37 \%$ ) as a source of aluminum and Césacol (colloidal solution $40 \%$, purchased from Rhone-Poulenc Specialty Chemicals) as the silicon source. The organic ion is tetramethylammonium hydroxide as $\mathrm{TMAOH} .5 \mathrm{H} 2 \mathrm{O}$ from Fluka. Other reagents used are the sodium hydroxide pellets from Prolabo, and deionized water.

\section{Synthesis}

We used the method described by Kerr (Kerr, 1961 and 1966) slightly modified with a fixed molar composition from: $8 \mathrm{TMA}_{2} \mathrm{O}, 1.46 \mathrm{Na}_{2} \mathrm{O}, 1 \mathrm{Al}_{2} \mathrm{O}_{3}, 5.33 \mathrm{SiO}_{2}, 320 \mathrm{H}_{2} \mathrm{O}$. An example of synthesis consists in dissolving $3 \mathrm{~g}$ of $\mathrm{SiO}_{2}$ in $64 \mathrm{~mL}$ of TMAOH 2.5M (representing $14.38 \mathrm{~g}$ of pure TMAOH). This operation is carried with constant stirring for 3 days in a Teflon flask. Aluminate solution was prepared from aluminum hydroxide $(1.46 \mathrm{~g})$ dissolved in the sodium hydroxide solution $(1.09 \mathrm{~g} \mathrm{NaOH})$ by heating and to which were added $45.5 \mathrm{~cm} 3$ of is distilled water. Aluminate gel so obtained is poured into the silicate solution with vigorous stirring for $150 \mathrm{~min}$; the mixture was aged at $30{ }^{\circ} \mathrm{C}$ for 48 to 72 hours and then heated in an oven for $24 \mathrm{~h}$ at $100^{\circ} \mathrm{C}$. The final product was washed, filtered and dried.

Exchanged forms divalent cations such $\mathrm{Ca}^{2+}, \mathrm{Ni}^{2+}$ et $\mathrm{Co}^{2+}$ were obtained, in aqueous media, from a ZK4 sample totally recationated to sodium by $\mathrm{NaOH}$ treatment. Thus, 2 to $3 \mathrm{~g}$ of zeolite $\mathrm{Na}$-ZK4 previously calcined at $500{ }^{\circ} \mathrm{C}$ were put together with $50 \mathrm{~mL}$ of distilled water in a beaker and mixed to $100 \mathrm{~mL}$ of $0.1 \mathrm{M}$ of cation exchanger solution. After an amply contact time between the two phases under agitation at ambient temperature, the solution was filtered then dehydrated under vacuum at $400^{\circ} \mathrm{C}$.

\section{Characterization}

X-rays diffraction analysis is composed of a generator of X-rays (Philips brand PW 1710) and of a vertical goniometer equipped with $\mathrm{Cu} \mathrm{K}_{\alpha}$ radiation $(\lambda=1.5418 \AA)$. Indexation of the diffraction peaks in the cubic system Pm3m allows calculation of the lattice parameter of the zeolite ZK-4 by the relation $a=\left(h^{2}+k^{2}+l^{2}\right)^{1 / 2}$.

The gas adsorption measurements were carried out on a Micromeritics $2100 \mathrm{E}$ entirely automated, which includes an introduction part with two pressure sensors connected to vacuum and gas inlets. The adsorption part comprises a cell containing the sample in a thermostatic chamber and a device for nitrogen by pressurizing pumping is connected to a temperatures regulator to achieve the desired temperature quickly. The micropores volume accessible $V_{m}$ to the adsorbate for an activated zeolite is calculated by (Gurvitsch, 1915):

$$
\mathrm{V}_{\mathrm{m}}=\frac{\mathrm{n}_{\mathrm{S}}}{\rho_{\mathrm{T}}} \mathrm{M}
$$

With $n_{S}$ : mole of adsorbate per unit mass of adsorbent; $\rho_{T}$ : density of the liquid adsorbate at the temperature T and $M$ : molecular weight of the adsorbate. In this study, we report our results in $n_{a}$ number of molecules per cavity $\alpha$ (abbreviated: :molec. $\mathrm{cav}^{-1}$ ) and therefore the correspondence between $\mathrm{cm}^{3}$ STP. $\mathrm{g}^{-1}$ and molec. $\mathrm{cav}^{-1}$ was deduced from the chemical formula of the zeolite $\mathrm{ZK}-4(\mathrm{Si} / \mathrm{Al}=1.78)$ and amounted to:

$$
1 \text { molec. } \mathrm{cav}^{-1}=13.68 \mathrm{~cm}^{3} \mathrm{STP} \cdot \mathrm{g}^{-1}
$$

Morphological study by scanning electron microscopy SEM was performed on a JSM 6400 instrument from JEOL. 


\section{RESULTS AND DISCUSSION}

Table 1 shows the chemical composition of calcined samples; the $\mathrm{H}^{+}$cation was introduced to insure the crystal electro neutrality. Sodium zeolite has a Si / Al ratio of 1.78 and is slightly different in its varieties exchanged with cobalt and nickel while in the calcium zeolite, it drops to 1.29 .

Table 1: Chemical formulae and Si/Al ratio values of ZK-4 zeolite samples and their exchanged forms

\begin{tabular}{|c|c|c|c|}
\hline Designation & Chemical formula & Si/Al ratio & Lattice parameter $\boldsymbol{a}_{\mathbf{0}} / \boldsymbol{A}^{\mathbf{0}}$ \\
\hline $\mathrm{ZK} 4-1$ & $\mathrm{Na}_{8.33} \mathrm{H}_{0.31} \mathrm{Al}_{8.64} \mathrm{Si}_{15.38} \mathrm{O}_{48}, 22.18 \mathrm{H}_{2} \mathrm{O}$ & 1.78 & 12.158 \\
\hline $\mathrm{Ca}-81$ & $\mathrm{Na}_{1.60} \mathrm{Ca}_{4.26} \mathrm{H}_{0.37} \mathrm{Al}_{10.49} \mathrm{Si}_{13.51} \mathrm{O}_{48}, 24.82 \mathrm{H}_{2} \mathrm{O}$ & 1.29 & 12.238 \\
\hline
\end{tabular}

Deduced by XRD analysis, the lattice parameter is practically identical to the samples, indicating that no alteration has affected the zeolite structure. This is confirmed by microscopy SEM showing cubic crystallites with homogeneous dimensions $(\sim 3 \mu \mathrm{m})$ for the samples prepared; Tangles of these cubic forms and the observed overgrowths appear to be due to a secondary nucleation on the crystallites walls rather than a coalescence of two particles during their growth (figure 1).
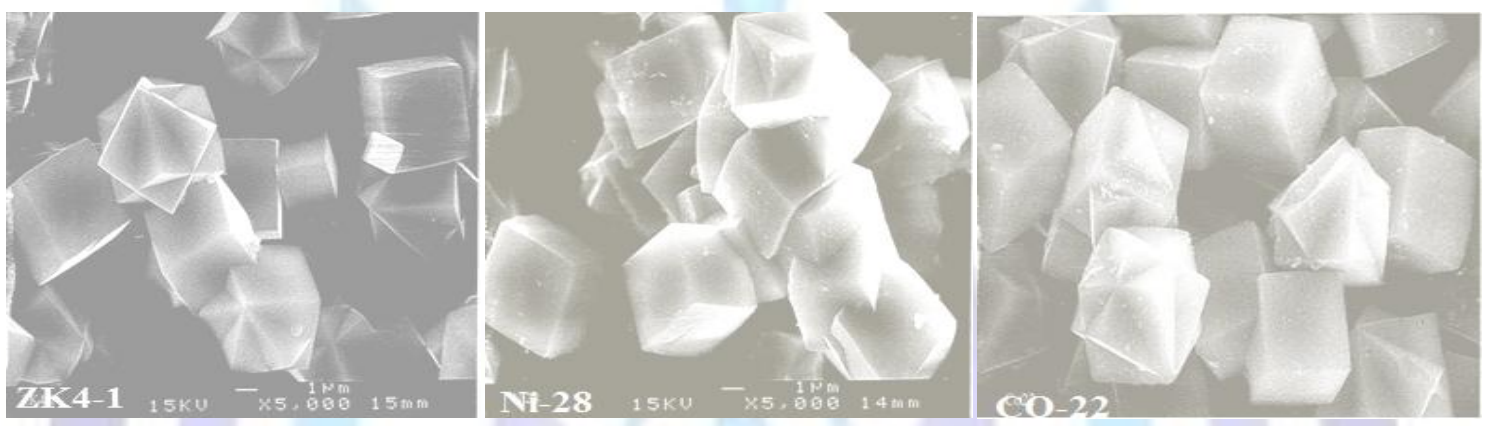

Figure 1: SEM pictures of zeolite crystals Na-ZK-4 and its varieties exchanged with nickel (Ni-28) and cobalt (Co22).

Adsorption of $\mathrm{O}_{2}$ (Fig. 2-a) and adsorption of $\mathrm{N}_{2}$ (Fig. 2-b) at $77 \mathrm{~K}$ is represented by isotherms for the variety samples of ZK-4, which are of type I according to IUPAC classification characteristic of microporous solids with a broad horizontal plateau over the whole domain of relative pressures.

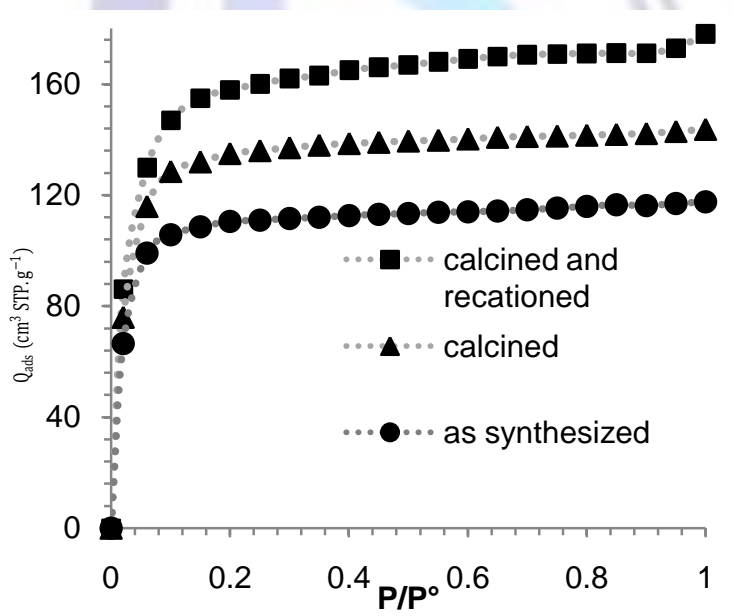

Figure 2-a: Oxygen adsorption isotherms at $77 \mathrm{~K}$ of zeolite ZK-4-1 (Si/Al=1.78) degassed under vacuum at $400{ }^{\circ} \mathrm{C}:(\square) \mathrm{Na}-\mathrm{ZK}-4$ calcined and recationised; $(\Delta)$ Na-ZK-4 calcined; (•) Na-ZK-4 as-synthesized.

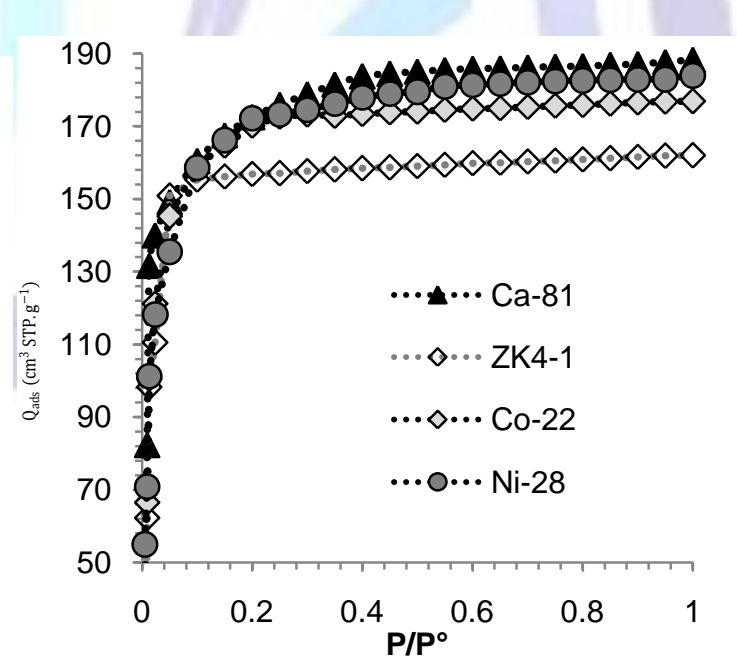

Figure 2-b: Nitrogen adsorption isotherms at $77 \mathrm{~K}$ on zeolite ZK-4 $(\diamond \mathrm{ZK}-4-1)$ and its varieties exchanged at: calcium $(\triangle)$ Ca-81, cobalt $(\bullet) \mathrm{Ni}-28$ and nickel $(\diamond) \mathrm{Ni}-28$.

Based on the interception ratio (IR) which is a good indication of micropores presence if $1<\mathrm{RI}<2.2$ (Kerr, 1961), the accessible microporous volumes to nitrogen and oxygen can be evaluated as shown in table 2; Thus, nitrogen penetrates into the sodium zeolite ZK-4, in contrast to zeolite $4 \mathrm{~A}$, suggesting that the cavity $\alpha$ becomes accessible to the $\mathrm{N}_{2}$ molecule, with the reduced number of $\mathrm{Na}^{+}$cations $(\geq 9)$ in the structure, instead of $12 \mathrm{Na}^{+}$in $4 \mathrm{~A}$ zeolite. 
Table 2: Values of accessible volume and RI criteria of $\mathrm{N}_{2}$ and $\mathrm{O}_{2}$ at $77 \mathrm{~K}$

\begin{tabular}{|c|c|c|c|c|}
\hline Samples & ZK-4-1 & Ca-81 & Ni-28 & Co-22 \\
\hline $\mathrm{RI}$ Criteria $/ \mathrm{N}_{2}$ & 1.029 & 1.057 & 1.048 & 1.041 \\
$\mathrm{RI}$ Criteria $/ \mathrm{O}_{2}$ & 1.009 & 1.008 & 1.014 & 1.002 \\
\hline$V_{m}\left(\mathrm{~nm}^{3} \mathrm{cav}^{-1}\right)$ accessible to $\mathrm{N}_{2}$ & 0.604 & 0.679 & 0.688 & 0.570 \\
\hline$V_{m}\left(\mathrm{~nm}^{3} \mathrm{cav}^{-1}\right)$ accessible to $\mathrm{O}_{2}$ & 0.524 & 0.572 & 0.573 & 0.519 \\
\hline $\mathrm{V}_{\mathrm{m}}\left(\mathrm{N}_{2}\right) / \mathrm{V}_{\mathrm{m}}\left(\mathrm{O}_{2}\right)$ & & & & 1.098 \\
\hline
\end{tabular}

To verify the localized character of adsorption in zeolite, we study the adsorption of nitrogen in the range $-80^{\circ} \mathrm{C}$ to $0{ }^{\circ} \mathrm{C}$ where adsorption takes place in the large cavity $\alpha$. The upper limit of $0^{\circ} \mathrm{C}$ is justified by the low adsorbed quantities. $\mathrm{n}_{\mathrm{a}} / \mathrm{P}$ vs. $n_{a}$ plots show that isotherms are fairly close to straight lines (figure 3 ), taking into account experimental errors in the domain $n_{a}<3$ which indicates that the Langmuir equation is applicable in this domain. The gradual exchange of $\mathrm{Na}^{+}$by divalent cations leads to concave curves, interpreted as a growing heterogeneity of adsorption sites; these straight lines intersect the x-axis to $n_{a}=5$ molec. $\mathrm{cav}^{-1}$ which implies the existence of five identical adsorption sites without interaction by cavity.
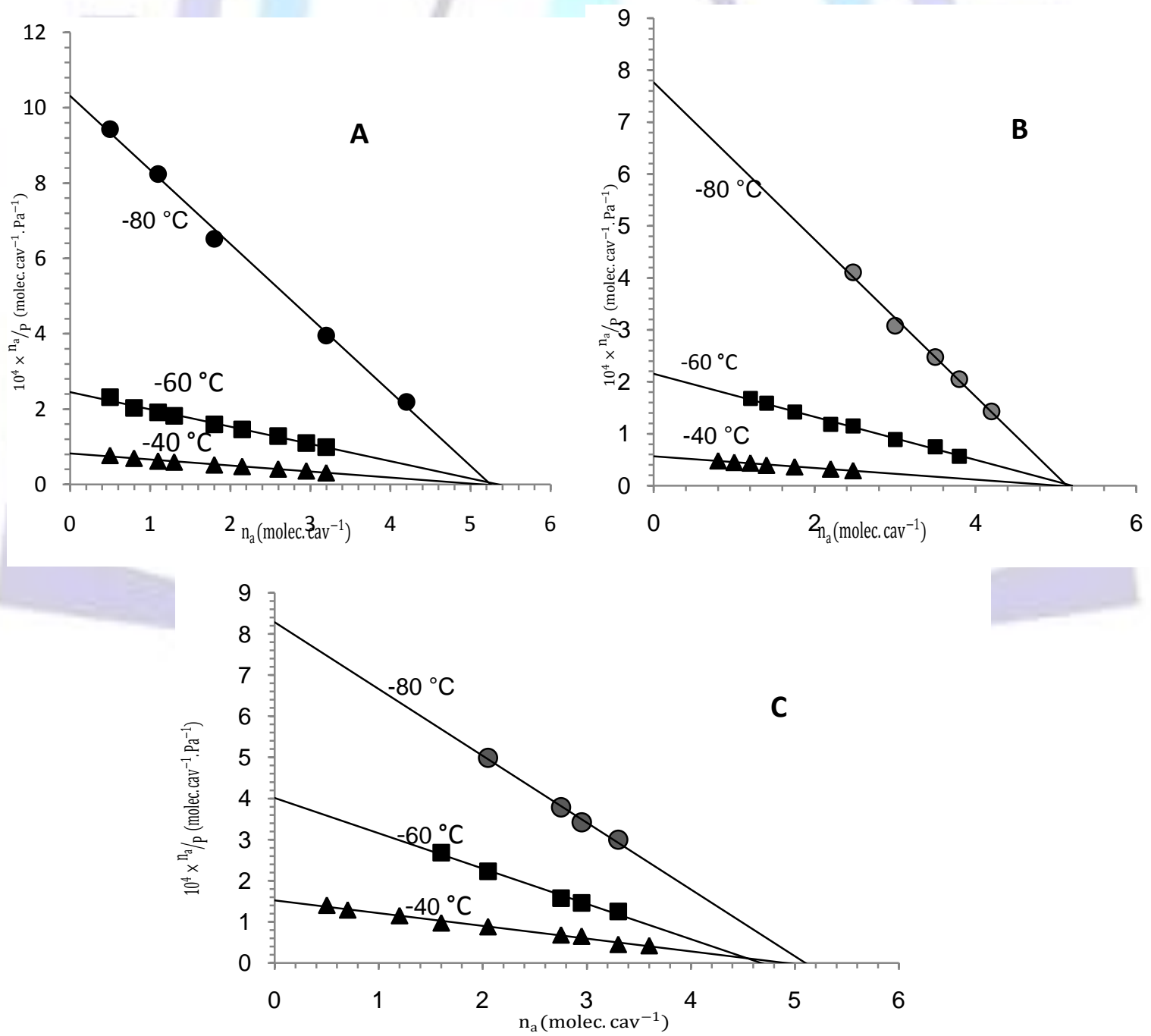

Figure 3: Nitrogen adsorption isotherms on A: zéolite ZK-4-1 (Si/Al=1.78); B: Co-22 and C: $\mathrm{Ni}-28$ at: $(\bullet)-80{ }^{\circ} \mathrm{C}$; (a) $-60^{\circ} \mathrm{C} ;(\triangle)-40^{\circ} \mathrm{C}$ and $(\longrightarrow$ Langmuir model to 5 sites. 
From there, table 3 shows the results after adjustment of the Langmuir equation parameters by fixing $n_{a}^{m}$ to five sites per cavity; it is observed that nitrogen adsorption onto ZK-4-1 is done on five equivalent sites, among of the eight sites I of the crystal unit cell. As for cationic varieties, the sites I of Co-22 sample contain respectively $6.6 \mathrm{Na}^{+}$and $0.97 \mathrm{Co}^{2+}$ or $6.3 \mathrm{Na}^{+}$ and $1.25 \mathrm{Ni}^{2+}$ for $\mathrm{Ni}-28$ sample suggesting that $\mathrm{Na}^{+}$constitute privileged adsorption sites compared to the divalent cations which are more inserted in the 6 oxygen-ring. However, it is more reasonable to think that the adsorption sites have a complex energy distribution.

Table 3: Langmuir equation parameters adjustments for each adsorbent-adsorbat couple (sites number fixed at 5)

\begin{tabular}{|c|c|c|c|}
\hline Designation & $\mathbf{k}_{\mathbf{0}} / \mathbf{P a}^{\mathbf{- 1}}$ & $\mathbf{U}_{\mathbf{0}} / \mathbf{k J} \cdot \mathbf{m o l}^{\mathbf{- 1}}$ & $-\operatorname{lnk}\left(\mathbf{0}^{\circ} \mathbf{C}\right)$ \\
\hline ZK4-1 & $5.2210^{-11}$ & 24.48 & 8.006 \\
\hline Co-22 & $1.1510^{-9}$ & 18.05 & 7.738 \\
\hline Ni-28 & $1.8710^{-8}$ & 14.36 & 6.575 \\
\hline
\end{tabular}

Propane molecule with critical diameter4.89A ${ }^{\circ}$ does not adsorb onto zeolite $\mathrm{Na}-\mathrm{A}$ to ambient, whereas in Ca-A, the adsorption capacity is 0130 grams adsorbate per gram of zeolite ${ }^{12}$. Propane adsorption isotherms are of type I for ZK-4-1 and Ca-81samples and much more propane is adsorbed in the zeolite exchanged with calcium than the sodic zeolite for both temperatures (figure 4). In $n_{a} / P$ vs. $n_{a}$ plot, the Langmuir model describe the propane adsorption onto Ca-81 sample for a number of sites touched by adsorption that not exceed $2\left(\mathrm{n}_{\mathrm{a}}<1.5\right.$ molec. cav $\left.^{-1}\right)$, much fewer than those engaged in nitrogen adsorption as shown in figure 5.

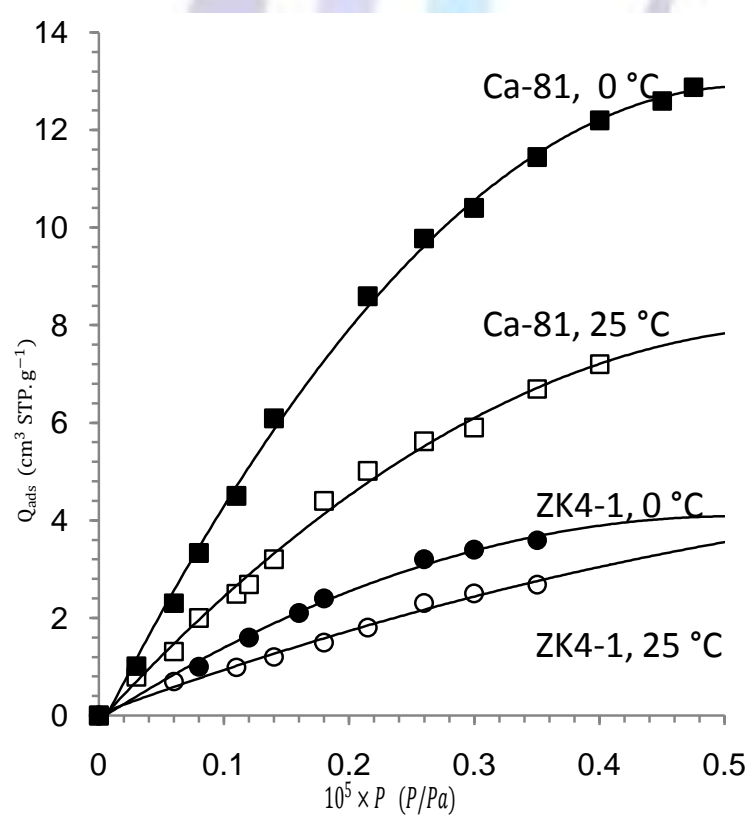

Figure 4: $\mathrm{C}_{3} \mathrm{H}_{8}$ adsorption isotherms on zeolite $\mathrm{ZK}-4$ and Ca-81at $0^{\circ} \mathrm{C}(\bullet \mathrm{ZK}-4-1 ; \mathrm{Ca}-81)$ and $25^{\circ} \mathrm{C}(\circ \mathrm{ZK}-$ 4-1; $\square$ (a-81).

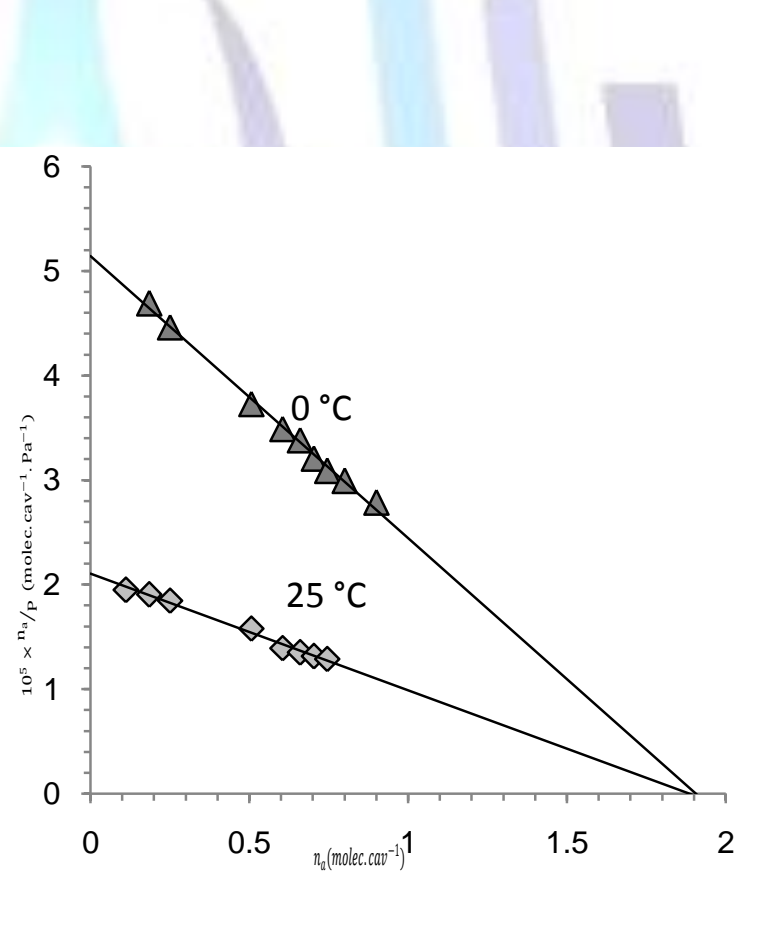

Figure 5: Adsorption isotherms of $\mathrm{C}_{3} \mathrm{H}_{8} / \mathrm{Ca}-81$ couple in coordinates: $\mathbf{n}_{\mathrm{a}} / \mathbf{p}=\mathbf{f}\left(\mathbf{n}_{\mathrm{a}}\right)$ at $0^{\circ} \mathrm{C}(\bullet)$ and $25^{\circ} \mathrm{C}(\mathrm{a}) ;(-)$ theoretical curve of Langmuir.

We can explain, in the case of the sodium form, by the fact that, the propane molecule exhibiting neither double bond nor quadrupole or dipole moment, does not have a required orientation relative to the surface. It is therefore less sensitive to the nature of the cation and two neighboring molecules may have with respect to each other in the most energetically favorable way, which explains the large lateral interaction. For the calcium form, it thus seems that the accessible $\mathrm{Ca}^{2+}$ cation to propane molecule is a significant factor in favour of a localised adsorption by being more polarizing than $\mathrm{Na}^{+}$and could be explained by an adsorption of one $\mathrm{C}_{3} \mathrm{H}_{8}$ molecule on $2 \mathrm{Ca}^{2+}$ together.

Calorimetric method has been used for $\mathrm{CO}_{2}$ and $\mathrm{C}_{2} \mathrm{H}_{4}$ uptakes at $25{ }^{\circ} \mathrm{C}$ to characterize the sites most accessible to adsorption. Figure 6 represents adsorption isotherms of $\mathrm{CO}_{2}$ in ZK-4-1 in coordinates $\mathrm{n}_{\mathrm{a}}=\mathrm{f}(\mathrm{P})$. wherein $n_{a}$ is equal to $13.68 \mathrm{~cm}^{3}$ STP. $\mathrm{g}^{-1}$ calculated for this type of zeolite. All isotherms are type I and corresponding to Langmuir equation,

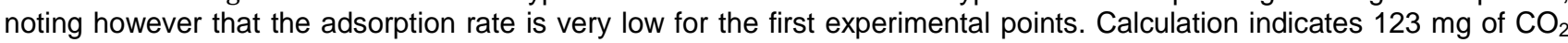
adsorbed per gram of zeolite ZK-4-1 at room temperature, which makes it as very good $\mathrm{CO}_{2}$ adsorbent. Figure 7 shows 
that $\mathrm{CO}_{2}$ adsorption at close to room temperature $\left(0-25{ }^{\circ} \mathrm{C}\right)$, affects a number of nearby five sites by lattice, so characteristic of the localized adsorption without lateral interactions while the slight concavity upwards is due to certain energy heterogeneity.

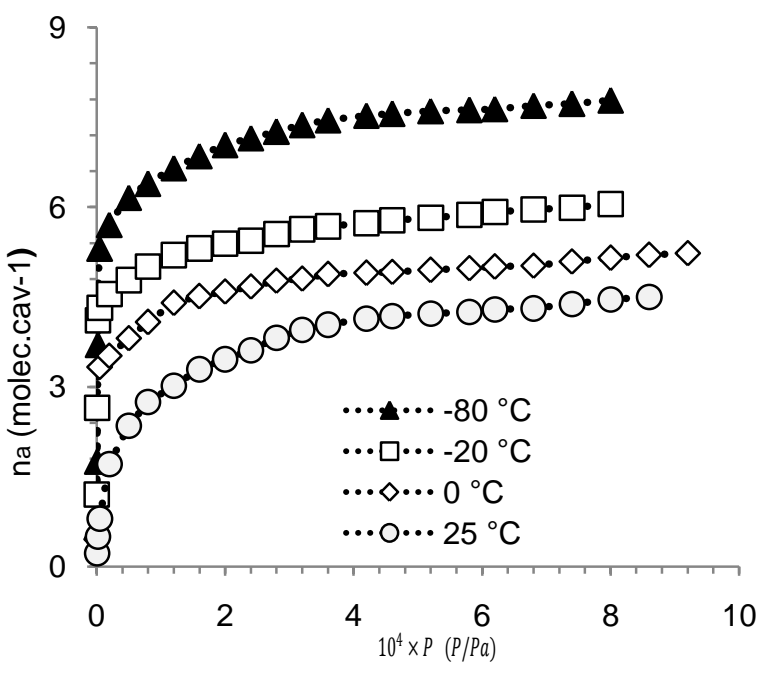

Figure 6: $\mathrm{CO}_{2}$ sorption isotherms on zeolite $\mathrm{ZK}-4-1$ : $(\Delta)-80^{\circ} \mathrm{C}$; (口) $-20^{\circ} \mathrm{C}$; ( $\left.\diamond\right) 0^{\circ} \mathrm{C}$; (०) $25^{\circ} \mathrm{C}$

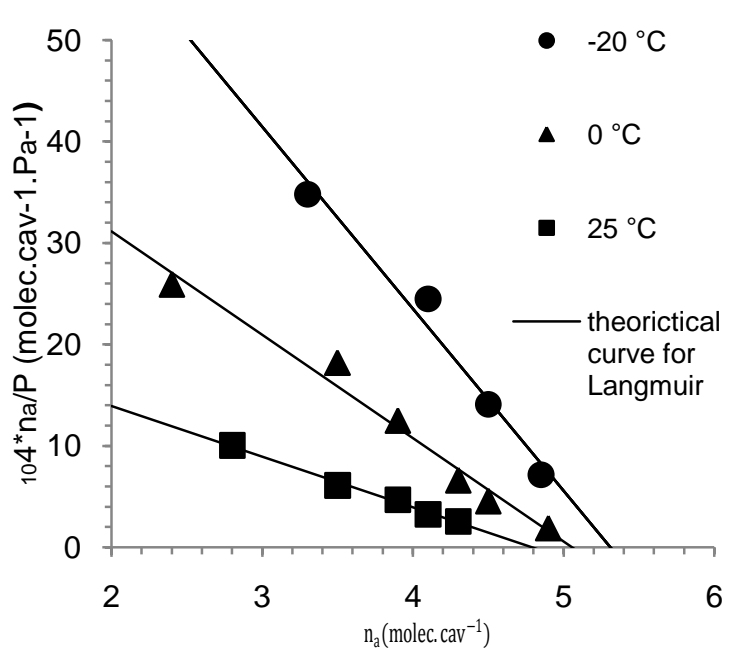

Figure 7: Langmuir model applied to the $\mathrm{CO}_{2}$ sorption in ZK-4-1 in coordinates: $\mathbf{n}_{\mathrm{a}} / \mathbf{p}=\mathbf{f}\left(\mathbf{n}_{\mathrm{a}}\right):(\bullet)$ $20^{\circ} \mathrm{C} ;(\Delta) 0^{\circ} \mathrm{C}$; ( $\left.\square\right) 25^{\circ} \mathrm{C}$; (- ) theoretical curve of Langmuir

Heats of adsorption of $\mathrm{CO}_{2}$ measured in ZK-4-1 sample and exchanged forms (Fig. 8) show a value up to $80 \mathrm{~kJ}^{\mathrm{M} M \mathrm{I}^{-1}}$ for the first gas introduction $\left(<0.029\right.$ molec. cav $\left.^{-1}\right)$ in all samples; However, they do not enable to say if a $\mathrm{CO}_{2}$ chemisorption occurs for low adsorbed amounts. Similarly, after cation exchange, the fact that only the first introduction of $\mathrm{CO}_{2}$ result in a relatively high heat of adsorption (80-90 $\mathrm{kJ}$. Mol${ }^{-1}$ ) does not assume that there is another type of site where takes place chemisorptions. This is not comparable with those obtained for the $4 \mathrm{~A}$ zeolite which is about $120 \mathrm{~kJ}^{\mathrm{mol}}{ }^{-1}$, and which calorimetry and IR spectroscopy studies indicate the chemisorptions onto zeolite 4A (Ginoux and Bonnetain, 1991; Amari et al., 1994; Delaval et al.,1986; Takaishi et al., 1975) leading to two possible forms: carboxylate or carbonate; it explains the high heats observed for $n_{a}$ less than 0.3 molec.cav ${ }^{-1}$. The principal $\mathrm{CO}_{2}$ adsorption sites in the ZK-4 zeolite are of type $\mathrm{Na}(\mathrm{I})$, responsible of a strong heat of physical absorption and absence of the $\mathrm{CO}_{2}$ chemisorptions in ZK-4 could be explained starting from the assumption that $\mathrm{CO}_{2}$ is chemically absorbed on a cationic pair, in fact the missing $\mathrm{Na}$ (II) - $\mathrm{Na}$ (III) pair in ZK-4 (Ginoux, 1983). Thus, these results may indicate the existence of energetically equivalents adsorption sites, characteristic of physisorption in a very wide range of adsorbed amounts.

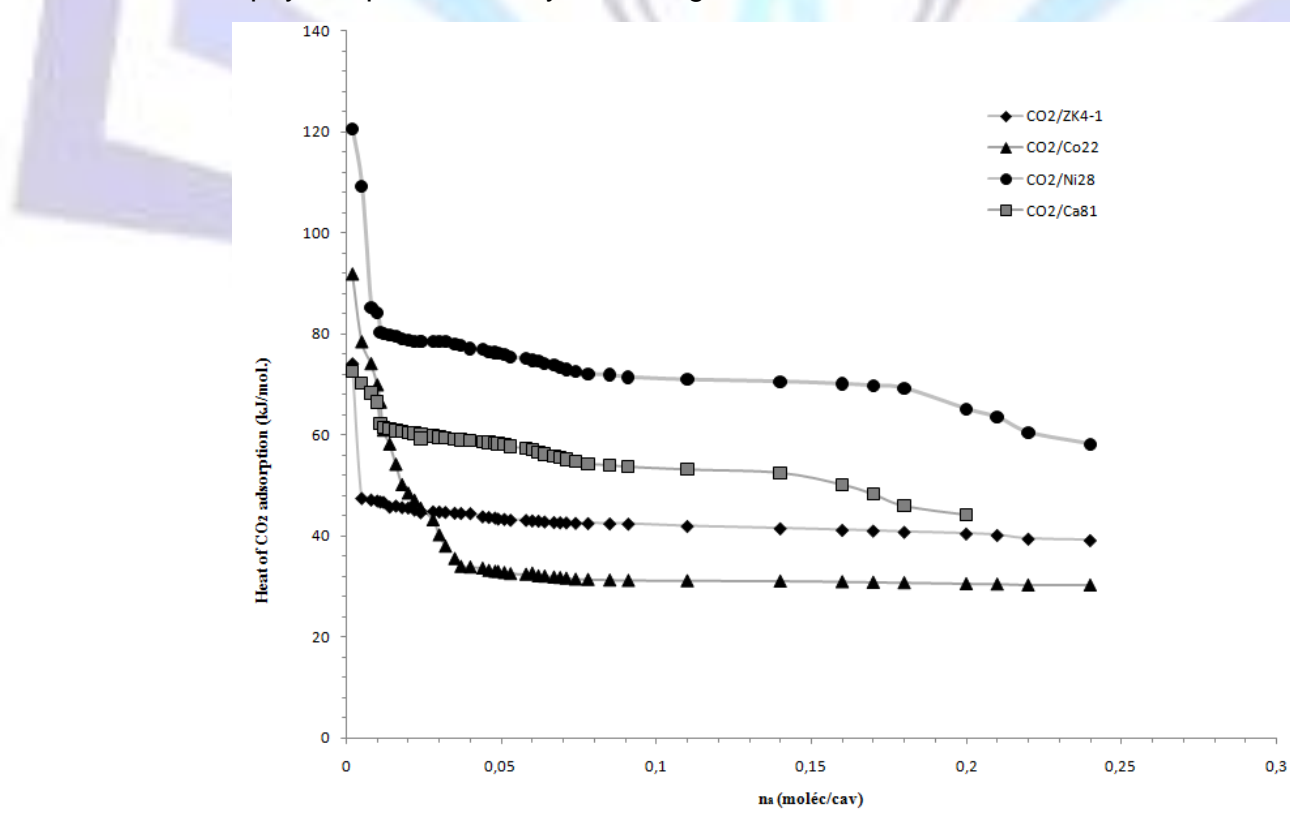

Figure 8: Enthalpies of $\mathrm{CO}_{2}$ adsorption onto zeolite ZK-4 and its varieties exchanged with divalent cations: ( ZK4-1; (A) Co-22; (•) Ni-28; (घ) Ca-81 


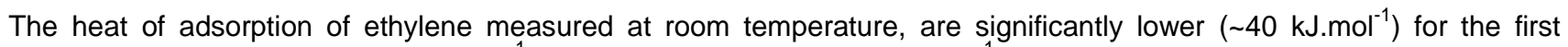
introductions and stabilize at $30 \mathrm{~kJ} \mathrm{~mol}^{-1}$ over the domain $n_{a}<2$ molec.cav ${ }^{-1}$ with significant difference between samples (Fig. 9). It appears for ZK-4-1 sample that all sites are energetically equivalents (4 or more) per cavity $\alpha$, attributable to the cations $\mathrm{Na}^{+}$in site I. When divalent cations replace the sodium, the behavior of the zeolite with respect to ethylene changes compared with it was with the sodium form of the zeolite. There is increasing initial energy of interaction with the nature of the cation. Presumably polarizing power of the exchanged cations in the structure is not completely converted into energy of interaction cation-adsorbate, probably due by a displacement of sites I towards the $\beta$ cavity. Ultimately, the mixed influence of the introduction of divalent shows that the adsorption of $\mathrm{C}_{2} \mathrm{H}_{4}$ may well is by the interaction of $\pi$-electrons with all cation-6-oxygen rings and not only with the assumed cation invariably exposed to the adsorbate.

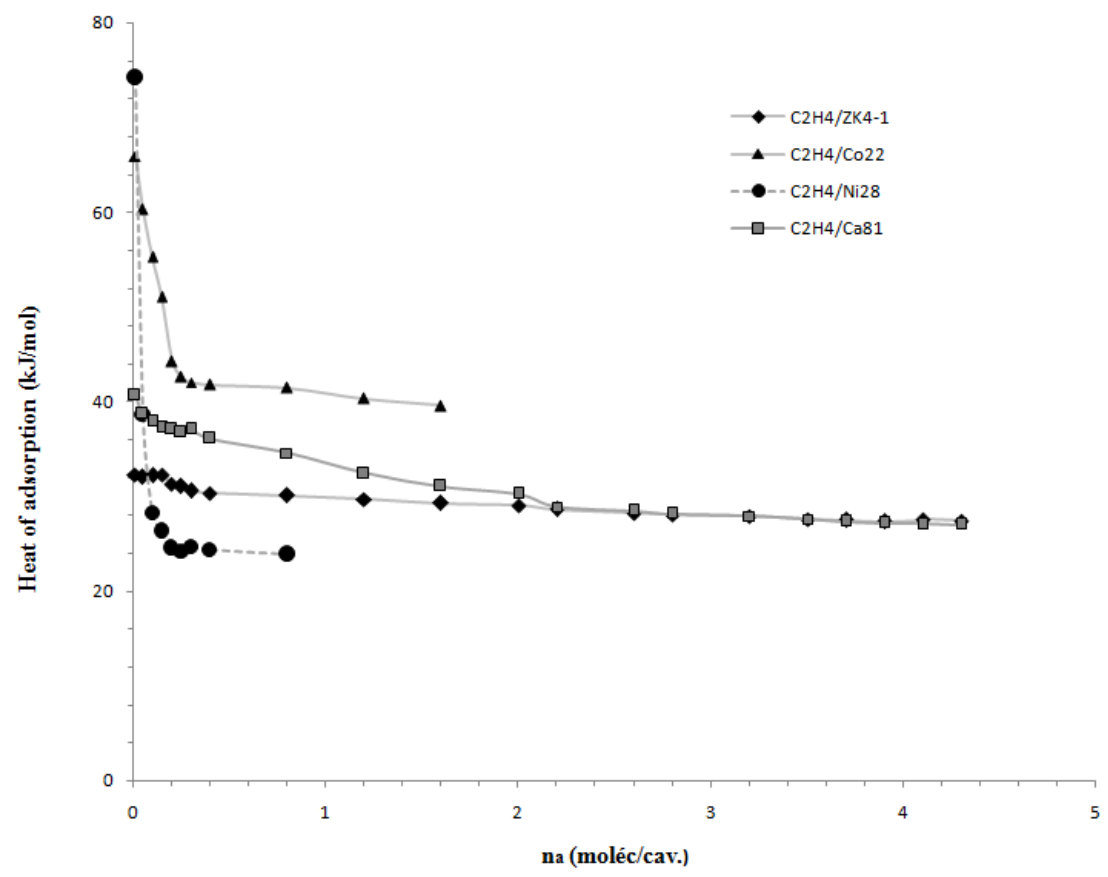

Figure 9: Enthalpies of $\mathrm{C}_{2} \mathrm{H}_{4}$ adsorption on zeolite $\mathrm{ZK}-4$ and its varieties exchanged with divalent cations: (

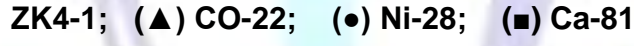

\section{CONCLUSION}

$\mathrm{N}_{2}$ adsorption onto ZK-4 zeolite in sodic form and exchanged with nickel and cobalt $(<30 \%)$ at temperatures close to ambient allowed the identification of five sites of adsorption, probably the cationic sites $\mathrm{Na}$ I. The adsorption of $\mathrm{C}_{3} \mathrm{H}_{8}$ is done in a localised way on the variety of ZK-4 exchanged with calcium whereas the sodium form lets think that $\mathrm{Na}^{+}$ions less polarizing than $\mathrm{Ca}^{2+}$ one are responsible for very energetic interactions adsorbate -adsorbent that cannot be described by Langmuir model. Even it does not generate chemisorptions, a relatively high enthalpy of adsorption has been observed in the range of small quantities of $\mathrm{CO}_{2}$ adsorbed. The absence of this one is attributed to the cations absence in site II and III. Heats of about $30 \mathrm{~kJ} \mathrm{Mol}^{-1}$ are noted in the case of $\mathrm{C}_{2} \mathrm{H}_{4}$ adsorption onto Na-ZK-4 for the entire range till 5 molecules/ cavity which is the ethylene adsorption limit. For the studied $n_{a}$ range, the heat of adsorption become important with weak adsorbed quantities, in the case of cationic forms of nickel and cobalt to stabilize then at 28 $\mathrm{kJ} \mathrm{Mol}^{-1}$. This phenomenon is due to the strong interaction which is created between the divalent cations and the ethylene molecule mitigated by a more or less large sinking of the cation in the 6-oxygen ring.

\section{ACKNOWLEDGMENTS}

This work is the result of a financial cooperation supported by the Algerian Ministry of Higher Education and the financial contribution of the Algerian-Spanish Convention AECID. We thank posthumously Dr. Jean-Louis GINOUX the invaluable support that allowed carrying out the work.

\section{REFERENCES}

[1] Meier W. M., Olson D. H., Atlas of Zeolite Structure Types, Butterworth's (1987)

[2] Kerr G. T., Chemistry of Crystalline Aluminosilicates II, synthesis and Properties of Zeolite ZK-4. J. Inorg. Chem.1966, 5, 1537

[3] Melchior M. T., Vaughan D. E. W., Jarman R. H., Jacobson A. J., The characterization of Si-Al ordering in A-type zeolite (ZK4) by ${ }^{29}$ Si NMR. Nature 1982, 298, 455 
[4] Ikeda, Kodaira, T. Oh T., Nisawa A., $\mathrm{K}^{+}$ion distribution in zeolite ZK-4's with various Si/Al ratios and the contribution of $\mathrm{K}^{+}$ions to $\mathrm{K}$ cluster formation. Microporous Mesoporous Materials 2003, 57, 249

[5] Kerr G. T., Factors Affecting The Formation of Zeolite A. J. Phys. Chem. 1966, 70, 1047

[6] Leiggener C., Currao A., Calzaferri G., Zeolite A and ZK-4 Materials Synthesis, A practical Guide. Ed. U. Schubert, N. Hüsing and R. Laine, Springer 2008, 21

[7] Eddy M.M., Cheetham A. K., David W.I.F., Powder neutron diffraction study of zeolite Na-ZK-4; an application of new functions for peak shape and asymmetry. Zeolites 1986, 6, 449

[8] Oh T., Yu J-S., Ikeda T., Kodaira T., Formation of K clusters in K-form zeolite ZK-4's with Si/Al>1. Solid State Communications 2002,123, 387

[9] Sadło J., J. Michalik J., L. Kevan L., EPR and ESEEM study of silver clusters in ZK-4 molecular sieves. NUKLEONIKA 2006, 51,49

[10] Mehmet Zahmakiran M., Preparation and characterization of LTA-type zeolite framework dispersed ruthenium nanoparticles and their catalytic application in the hydrolytic dehydrogenation of ammonia-borane for efficient hydrogen generation. Materials Science and Engineering 2012, B 117, 606

[11] Gurvitsch L. G., J. Phys. Chem. Soc. Russ. 1915, 47, 805

[12] Kerr G. T., US Patent 3314752A, USPTO 1961

[13] Ginoux J-L., Bonnetain L., In Characterization of Porous Solids II, Ed. Elsevier 1991, 189

[14] Amari D., Ginoux J-L., Bonnetain L., Textural damage of cation-exchanged LTA zeolites studied by gas adsorption. Zeolites 1994,14, 58

[15] Delaval Y, Seloudoux R, Cohen De Lara E, Determination of isotherms and initial heat of adsorption of $\mathrm{CO}_{2}$ and $\mathrm{N}_{2} \mathrm{O}$ in 4A zeolite from infrared measurements. J. C. S. Faraday Trans.1986, 1, 82, 365

[16] Takaishi T, Yatsurugi Y, Yusa A., Kuratomi T, Changes in the sieving action and thermal stability of zeolite a produced by ion-exchange. J. C. S. Faraday Trans.1975, 1, 71, 97

[17] Ginoux J-L., PhD Thesis, Institut National Polytechnique de Grenoble 1983 